\title{
Effect of diode laser trans-scleral cyclophotocoagulation in the management of glaucoma after intravitreal silicone oil injection for complicated retinal detachments
}

\author{
Soo Kyung Han, Ki Ho Park, Dong Myung Kim, Bong Leen Chang
}

\begin{abstract}
Aims - To evaluate the effect of trans scleral cyclophotocoagulation (TSCPC) on intraocular pressure (IOP) in the eyes retaining intravitreal silicone oil with medically uncontrolled secondary glaucoma following intravitreal silicone oil injection.

Methods-Medical records of 11 eyes of 11 patients who underwent TSCPC for medically uncontrolled glaucoma without pupillary block following intravitreal silicone oil injection for complicated retinal detachment were reviewed retrospectively. In all cases, intravitreal silicone oil was not removed for fear of retinal redetachment. Diode laser contact TSCPC was performed at a power of 1.5-2.5 W, for a duration of 2 seconds, and with 20-27 applications. IOP, number of glaucoma medications, and success rate were evaluated.

Results-After a mean follow up period of 52.5 (SD 8.2) (range 42-68) weeks, the mean pretreatment level of IOP, 43.0 (14.4) (26-67) $\mathrm{mmHg}$, had fallen to 14.5 (4.3) (7-20) $\mathrm{mm} \mathrm{Hg}(p=0.003)$. The number of glaucoma medications was reduced from $2.6(0.8)$ to $0.6(1.0)(p=$ $0.005)$. Qualified success was achieved in nine eyes $(81.8 \%)$ and complete success in six $(54.5 \%)$. After TSCPC, patients' retinal status had not changed.

Conclusion-Patients with medically uncontrolled glaucoma secondary to intravitreal silicone oil injection can be treated with TSCPC in spite of the retained intravitreal silicone oil.
\end{abstract}

(Br f Ophthalmol 1999;83:713-717)

Ophthalmology, Seoul

National University

College of Medicine,

Seoul, Korea

S K Han

K H Park

D M Kim

B L Chang

Correspondence to:

Ki Ho Park, MD,

Department of

Ophthalmology, Seoul

National University College

of Medicine, 28 Yongon

dong Chongno gu, Seoul

110-744, Korea.

Accepted for publication 16 December 1998 silicone oil has not yet been reported, however.
We retrospectively reviewed the course of postoperative IOP in patients who underwent TSCPC for medically uncontrolled secondary glaucoma following intravitreal silicone oil injection for complicated retinal detachment.

Subjects and methods

Between 1 April 1996 and 31 July 1997, surgery for the management of medically uncontrolled glaucoma secondary to intravitreal silicone oil injection was performed at Seoul National University Hospital on 11 eyes of 11 consecutive patients who had given their informed consent.

Medically uncontrolled glaucoma was defined as occurring (1) when IOP was equal to or higher than $25 \mathrm{~mm} \mathrm{Hg}$, in spite of the use of two or more antiglaucoma medications, and (2) when eyeball pain, headache, or a sign of corneal oedema presented as a secondary symptom. Patients with severe ocular pain or severe corneal decompensation due to increased IOP underwent TSCPC, even though they had no light perception. Patients with advanced glaucoma intolerant of antiglaucoma medications (for example, oral acetazolamide in patients with severe diabetic nephropathy) in an attempt to reduce or stop medications were also included in this study. Eyes with pupillary block were not treated by TSCPC. ${ }^{5}$ Eyes with a diagnosis of glaucoma antedating silicone oil injection, or with a history of filtering, implant, or cyclodestructive surgery did not undergo TSCPC.

Of the 11 patients who underwent TSCPC, nine were men and two were women; their mean age was 46.9 (SD 9.2) (range 29-63) years. The mean follow up period was 52.5 (8.2) (42-68) weeks.

At the time of silicone oil injection, three patients (cases 1, 7, 10) presented with combined rhegmatogenous and tractional retinal detachment associated with high risk proliferative diabetic retinopathy, one patient (case 3) presented with traumatic retinal detachment, three patients (cases 2, 5, 8) presented with proliferative vitreoretinopathy ${ }^{6}$ with aphakic or pseudophakic retinal detachment after cataract extraction or clear lens extraction, and four patients (cases $4,6,9,11$ ) presented with severe proliferative vitreoretinopathy ${ }^{6}$ with rhegmatogenous retinal detachment (Table 1). The mean number of operations before TSCPC was 3.4 (SD 1.1) (range 2-5). Seven patients (cases 1, 2, 5, 8, 9, $10,11)$ had corneal subepithelial oedema and 
Table 1 Patient data

\begin{tabular}{|c|c|c|c|c|c|c|c|c|c|c|c|}
\hline $\begin{array}{l}\text { Case } \\
\text { no }\end{array}$ & Age & Sex & $\begin{array}{l}\text { Underlying } \\
\text { pathology }\end{array}$ & Previous surgery & $\begin{array}{l}\text { Corneal } \\
\text { oedema }\end{array}$ & $\begin{array}{l}\text { Silicone oil } \\
\text { emulsification }\end{array}$ & $\begin{array}{l}\text { Anterior } \\
\text { chamber } \\
\text { angle }\end{array}$ & Lens & $\begin{array}{l}\text { Inferior } \\
\text { peripheral } \\
\text { iridectomy }\end{array}$ & $\begin{array}{l}\text { Duration } \\
\text { between } \\
\text { SOI and } \\
\text { IIOP }\end{array}$ & $\begin{array}{l}\text { Duration } \\
\text { between } \\
\text { IIOP and } \\
\text { TSCPC }\end{array}$ \\
\hline 1 & 50 & $M$ & DMTRD & $\mathrm{ECCE}+\mathrm{PCL}, \mathrm{Vit}, \mathrm{SOI}$ & subepithelial & not emulsified & open & pseudophakia & No & 7 days & 4 days \\
\hline 2 & 61 & $\mathrm{M}$ & PVRC5 & ECCE, Vit, Vit + SOI & subepithelial & emulsified & open & aphakia & Yes & 6 day & 14 months \\
\hline 3 & 52 & M & PVRC3 & SBE, ECCE, Vit, SOI & stromal & not emulsified & total PAS & aphakia & Yes & 2 day & 16 months \\
\hline 4 & 56 & M & PVRC5 & SBE +Vit +Lens, FGE, SOI & clear & emulsified & open & aphakia & Yes & 8 months & 29 months \\
\hline 5 & 29 & M & PVRC2 & $\begin{array}{l}\text { CLE+PCL, SBE, Vit, FGE, Vit } \\
\text { +SOI }\end{array}$ & subepithelial & emulsified & open & pseudophakia & No & 12 day & 2 months \\
\hline 6 & 37 & $M$ & PVRC5 & SB, SBE + Vit +Lens, FGE, Vit +SOI & clear & emulsified & open & aphakia & Yes & 2 months & 34 months \\
\hline 7 & 54 & $\mathrm{~F}$ & DMTRD & Vit, Lens + SOI & stromal & emulsified & open & aphakia & Yes & 15 months & 26 months \\
\hline 8 & 48 & M & PVRC2 & $\begin{array}{l}\text { ECCE +PCL, SBE, Vit, PCLR +Vit } \\
\text { +SOI }\end{array}$ & subepithelial & not emulsified & open & aphakia & Yes & 9 months & 7 months \\
\hline 9 & 33 & M & PVRC5 & Vit, Vit +Lens, FGE, SOI & subepithelial & emulsified & total PAS & aphakia & Yes & 2 months & 28 months \\
\hline 10 & 33 & M & DMTRD & $\mathrm{PE}+\mathrm{PCL}+\mathrm{Vit}, \mathrm{PCLR}+\mathrm{Vit}+\mathrm{SOI}$ & subepithelial & emulsified & open & aphakia & Yes & 1 day & 20 days \\
\hline 11 & 63 & $\mathrm{~F}$ & PVRC2 & SBE + Vit, FGE, Vit +Lens +SOI & subepithelial & emulsified & open & aphakia & Yes & 11 months & 9 months \\
\hline
\end{tabular}

DMTRD = diabetic retinopathy with tractional retinal detachment; PVR = proliferative vitreoretinopathy; ECCE = extracapsular cataract extraction; PCL = posterior chamber lens implantation; Vit = vitrectomy; SOI = silicone oil injection; Lens = lensectomy; PE = phacoemulsification; PCLR = posterior capsular lens removal; $\mathrm{SBE}=$ scleral buckling with encircling; $\mathrm{CLE}=$ clear lens extraction; FGE = fluid-gas exchange; SB = scleral buckling; IIOP = increased intraocular pressure

${ }^{\star}$ Grading of PVR was based on the classification of proliferative vitreoretinopathy used in the silicone study. ${ }^{6}$

two (cases 3,7 ) had stromal oedema secondary to high IOP. Two eyes (cases 3, 9) showed total peripheral anterior synechiae, with a patent inferior iridectomy site without pupillary block. In seven patients (cases $2,3,4,5,6,9$, 11), emulsified silicone oil was seen in the anterior chamber. All patients were aphakic or pseudophakic after surgery; all in the former category underwent inferior iridectomy at the time of silicone oil injection. In all of two pseudophakic eyes without previous inferior iridectomy, the pupillary block component did not contribute to the IOP elevation.

The mean overall follow up period between intravitreal silicone oil injection and TSCPC was 77.6 (SD 59.6) (range 1.2-164) weeks. Glaucoma was diagnosed, on average, 17.6 (21.6) weeks (1 day to 60 weeks) after silicone oil injection. TSCPC was performed 60.0 (49.6) weeks (4 days to 136 weeks) after the diagnosis of glaucoma.

Average baseline IOP was 43.0 (14.4) (26-67) $\mathrm{mm} \mathrm{Hg}$, and preoperative visual acuity ranged from $20 / 200$ to no light perception. The patients had been taking two to five glaucoma medications, with an average of 2.6 (0.8). Two of the patients (cases 7,10 ) had rubeosis iridis without any new vessels at the anterior chamber angle. In all eyes the retina at the macula was flat, while in three an inferior shallow elevation of the retina was seen. Owing to possible complications such as retinal detachment and phthisis, surgeons were-in all cases-reluctant to remove silicone oil.

TSCPC was performed after retrobulbar injection of $2-4 \mathrm{ml}$ of $2 \%$ lignocaine. A semiconductor diode laser system (Oculight SLx, Iris Medical Instruments, Mountain View, CA, USA) was used; its maximum power output was $2.5 \mathrm{~W}$, and maximum duration 9.9 seconds. A $600 \mu \mathrm{m}$ diameter laser delivery quartz fibreoptic (G-probe, Iris Medical Instruments, Mountain View, CA, USA), its planar polished end protruding $0.7 \mathrm{~mm}$ from a handpiece and fabricated in a shape which encouraged accurate fibreoptic location, was centred $1.2 \mathrm{~mm}$ behind the surgical limbus and oriented parallel to the visual axis. Twenty to 27 laser applications, each of 2 seconds' duration, were delivered to all four quadrants of the circumference of the ciliary body, except for case 1 . In case 1 , the first case among the 11 cases, 14 laser applications were performed saving the temporal portion of the ciliary body because of relatively low pretreatment IOP. Starting from $1.75 \mathrm{~W}$, power was increased by $0.25 \mathrm{~W}$ up to $2.5 \mathrm{~W}$ if there was no tissue disruption reaction (a "pop" or "snap" from within the eye) during the two subsequent applications. If a "pop" sound occurred during more than one laser application, power was further reduced by $0.25-1.5 \mathrm{~W}$ and treatment was completed at this wattage. ${ }^{2}{ }^{3}$ Mean total energy delivered was calculated from the following equation: mean power $(\mathrm{W}) \times 2.0$ (seconds) $\times$ number of applications. It ranged from 56.0-114.8 J with the average, 88.0 (SD 20.0) J.

Following TSCPC, medication comprised $1 \%$ prednisolone eye drops four times a day, $1 \%$ atropine eye drops twice a day, and $0.3 \%$ ofloxacin ophthalmic ointment twice a day. IOP was monitored at 1 hour, 1 day, and 1, 2, $4,8,12,20,28$ weeks after the procedure. Ofloxacin $0.3 \%$ ointment was used for 2 weeks and topical steroid and atropine for 2 months. Antiglaucoma medications were tapered according to measured IOP. Topical antibiotics were prescribed routinely for the prophylaxis of

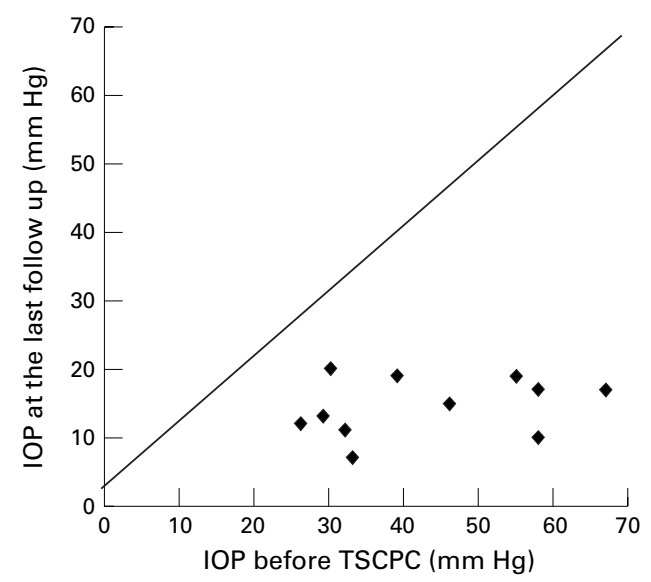

Figure 1 Scattergram showing intraocular pressure (IOP) before trans-scleral cyclophotocoagulation (TSCPC), against IOP at the last follow up. All 11 eyes showed IOP decreased after TSCPC and controlled under $21 \mathrm{~mm} \mathrm{Hg}$. 
Table 2 Summary of outcome

\begin{tabular}{|c|c|c|c|c|c|c|c|c|c|c|c|c|c|}
\hline \multirow[b]{2}{*}{ Case no } & \multirow{2}{*}{$\begin{array}{l}\text { Duration } \\
\text { of follow } \\
\text { up (weeks) }\end{array}$} & \multicolumn{2}{|c|}{$I O P(m m H g)$} & \multicolumn{2}{|l|}{$V / A$} & \multicolumn{2}{|c|}{$\begin{array}{l}\text { Ocular pain } \\
\text { or headache }\end{array}$} & \multicolumn{2}{|c|}{$\begin{array}{l}\text { No of antiglaucoma } \\
\text { medications }\end{array}$} & \multicolumn{2}{|l|}{ Retina } & \multirow{2}{*}{$\begin{array}{l}\text { Mean total } \\
\text { energy }^{\star}(\mathfrak{F})\end{array}$} & \multirow[b]{2}{*}{ Success } \\
\hline & & preop & postop & preop & postop & preop & postop & preop & postop & preop & postop & & \\
\hline 1 & 68 weeks & 26 & 12 & HM & $\mathrm{CF}$ & Yes & No & 3 & 0 & flat & flat & 56.0 & $\begin{array}{l}\text { complete } \\
\text { success }\end{array}$ \\
\hline 2 & 54 weeks & 55 & 19 & $\mathrm{CF}$ & NLP & Yes & No & 2 & 1 & flat & flat & 72.0 & failure \\
\hline 3 & 48 weeks & 58 & 17 & NLP & NLP & Yes & No & 2 & 0 & flat & flat & 114.8 & $\begin{array}{l}\text { complete } \\
\text { success }\end{array}$ \\
\hline 4 & 68 weeks & 29 & 13 & 0.1 & 0.1 & No & No & 2 & 0 & $\begin{array}{l}\text { inferior } \\
\mathrm{RD}\end{array}$ & $\begin{array}{l}\text { inferior } \\
\mathrm{RD}\end{array}$ & 101.3 & $\begin{array}{l}\text { complete } \\
\text { success }\end{array}$ \\
\hline 5 & 48 weeks & 46 & 15 & 0.02 & 0.1 & Yes & No & 3 & 0 & flat & flat & 70.0 & $\begin{array}{l}\text { complete } \\
\text { success }\end{array}$ \\
\hline 6 & 51 weeks & 58 & 10 & NLP & NLP & Yes & No & 2 & 0 & $\begin{array}{l}\text { inferior } \\
\text { RD }\end{array}$ & $\begin{array}{l}\text { inferior } \\
\text { RD }\end{array}$ & 108.0 & $\begin{array}{l}\text { complete } \\
\text { success }\end{array}$ \\
\hline 7 & 50 weeks & 67 & 17 & NLP & NLP & No & No & 2 & 2 & flat & flat & 101.3 & $\begin{array}{l}\text { qualified } \\
\text { success }\end{array}$ \\
\hline 8 & 50 weeks & 39 & 19 & 0.1 & 0.02 & Yes & No & 4 & 3 & flat & flat & 108.0 & $\begin{array}{l}\text { qualified } \\
\text { success }\end{array}$ \\
\hline 9 & 48 weeks & 33 & 7 & NLP & NLP & Yes & No & 3 & 0 & $\begin{array}{l}\text { inferior } \\
\mathrm{RD}\end{array}$ & $\begin{array}{l}\text { inferior } \\
\mathrm{RD}\end{array}$ & 92.0 & $\begin{array}{l}\text { complete } \\
\text { success }\end{array}$ \\
\hline 10 & 42 weeks & 30 & 20 & HM & NLP & No & No & 4 & 0 & flat & flat & 75.0 & failure \\
\hline 11 & 50 weeks & 32 & 11 & NLP & NLP & Yes & No & 2 & 1 & flat & flat & 70.0 & $\begin{array}{l}\text { qualified } \\
\text { success }\end{array}$ \\
\hline Mean (SD) & $52.5(8.2)$ & $43.0(14.4)$ & $14.5(4.3)$ & & & & & $2.6(0.8)$ & $0.6(1.0)$ & & & $88.0(20.0)$ & \\
\hline
\end{tabular}

$\mathrm{HM}=$ hand movements; NLP = no light perception; $\mathrm{CF}=$ counting fingers; inferior $\mathrm{RD}=$ peripheral retinal detachment confined to inferior retina

${ }^{\star}$ Mean total energy $=$ mean power $(\mathrm{W}) \times 2.0$ (seconds) $\times$ number of laser applications in the first treatment.

conjunctival infection due to any possible clinical or subclinical conjunctival burn. ${ }^{37}$

Follow up included determination of best corrected vision, IOP measurements with a Goldmann applanation tonometer, and slit lamp biomicroscopic and ocular fundus examinations.

Retreatment was performed after 8 weeks of follow up when the IOP was above $30 \mathrm{~mm} \mathrm{Hg}$ with at least two measurements 4 weeks apart in spite of maximum tolerable medical treatment.

In our series, we defined complete success as a final IOP equal to or lower than $21 \mathrm{~mm} \mathrm{Hg}$ without glaucoma medication, and qualified success as final IOP equal to or lower than 21 $\mathrm{mm} \mathrm{Hg}$ regardless of medication. Hypotony was defined as IOP lower than $5 \mathrm{~mm} \mathrm{Hg}$ on two examinations at least 4 weeks apart, and if this condition was found, the procedure was classified as a failure. Loss of light perception was also classified as a failure.

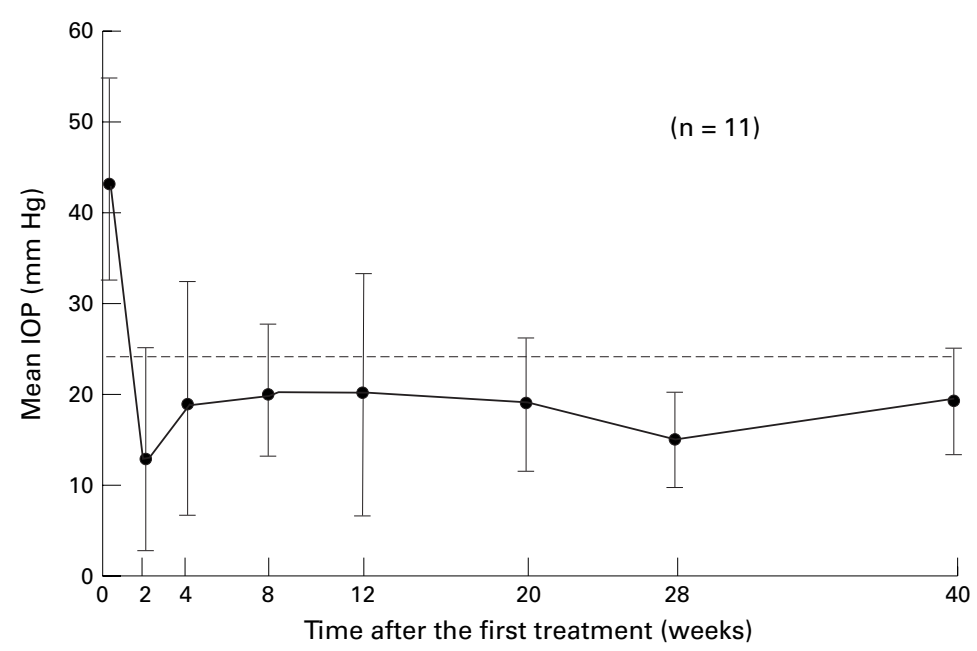

Figure 2 Mean intraocular pressure (IOP) against time after the first treatment; the decrease of IOP at all points including that of 40 weeks after the treatment was statistically significant $(p<0.05)$. The horizontal broken line represents an IOP of $21 \mathrm{~mm} \mathrm{Hg}$. The error bars represent $95 \%$ confidence interval.
Using Wilcoxon's signed rank test, pre- and post-TSCPC IOP and the number of medications were statistically compared. A p value less than 0.05 was considered significant.

\section{Results}

Overall changes in IOP following TSCPC are shown as a scattergram (Fig 1). During the last follow up, IOP of all 11 eyes was found to be less than before treatment. Pressure in all eyes $(100 \%)$ was under $21 \mathrm{~mm} \mathrm{Hg} 24$ and 25 weeks, respectively, after they were first treated, two of these (cases 5,8) required additional TSCPC.

After a mean follow up period of 52.5 (8.2) (42-68) weeks, mean pretreatment IOP, 43.0 (14.4) (26-67) $\mathrm{mmHg}$ had fallen significantly to 14.5 (4.3) (7-20) $\mathrm{mm} \mathrm{Hg}(\mathrm{p}=0.003$, Wilcoxon's signed rank test) (Table 2).

IOP change according to follow up time is shown in Figure 2. Mean IOP 24 hours after treatment was $17.5(5.4) \mathrm{mm} \mathrm{Hg}$; the individual IOP reduction ranged from 55 to -1 $\mathrm{mm} \mathrm{Hg}$ from baseline IOP. Only one eye was 1 $\mathrm{mm} \mathrm{Hg}$ above baseline at 24 hours. If mean IOP had fallen to within the normal range within 24 hours of TSCPC, this was maintained until the last follow up.

During the last follow up four eyes (36.4\%) (cases $2,7,8,11$ ) needed an average of 1.75 (1.3) antiglaucoma medications; seven $(63.6 \%)$ needed no medication. The number of antiglaucoma medications significantly decreased from $2.6(0.8)$ at baseline to $0.6(1.0)$ during the last follow up ( $\mathrm{p}=0.005$, Wilcoxon's signed rank test). In nine patients, best corrected visual acuity did not change, but in two it deteriorated; in one (case 2), this was from counting finger to no light perception, and in the other (case 10), from hand movements to no light perception (Table 2).

Eyeball pain, headache, and corneal oedema were not found during the last follow up, and no eye showed hypotony, hypopyon, band keratopathy, or change in the status of the retina. 
In case 5 IOP was well controlled without glaucoma medication on the 15 th day after the second treatment. Four months later, the silicone oil was removed because it was disturbing the visual axis; afterwards, the retina remained flat, IOP was well controlled, and there was no hypotony.

Qualified success, defined as a final IOP equal to or lower than $21 \mathrm{~mm} \mathrm{Hg}$ regardless of glaucoma medication without visual loss or hypotony, was achieved in nine eyes $(81.8 \%)$, and complete success, defined as a final IOP equal to or lower than $21 \mathrm{~mm} \mathrm{Hg}$ without glaucoma medication, in six eyes (54.5\%).

\section{Discussion}

In cases where complicated retinal detachments has occurred, the use of intravitreal silicone oil injection has shown encouraging results. However, late complications may preclude a satisfactory long term outcome; one of the most common of these is elevated IOP, with an incidence of between $6 \%$ and $48 \% .^{8-13}$

Although removing silicone oil is the current standard primary surgical management for such cases, there are many theories about the role of silicone oil in IOP elevation. Laroche et $a l^{14}$ noted normal IOPs even when silicone globules were present in the angle. Burk et $a l^{15}$ reported that the mechanism of IOP change did not appear to be directly related to the presence of silicone, but rather to the preoperative status of the eye and other aspects of vitreoretinal surgery; the most common pressure inducing factors appeared to be preoperative compromise of aqueous outflow facility, including peripheral anterior synechiae and chronic structural alterations in the trabecular meshwork compounded by early postoperative insults, such as haemorrhage and inflammation. De Corral et al ${ }^{16}$ suggested that rubeosis iridis, erythroclasis, haemolysis, mechanical causes (haemorrhage or silicone oil bubbles), inflammation, phacolysis, steroid responder, and pupillary block were possible causes of increased IOP after vitrectomy and intravitreal silicone oil injection. Moreover, removal of intraocular silicone oil in the setting of emulsification and postoperative glaucoma may not necessarily result in IOP reduction. Moisseiev et $a l^{17}$ reported that in $91 \%$ of the glaucomatous eyes, removal of the emulsified oil did not affect IOP.

The high incidence of retinal detachment after silicone oil removal deters a physician from removing this silicone oil for lowering IOP. Retinal redetachment has been reported up in to $33 \%$ of patients ${ }^{110}$ and Casswell and Gregor ${ }^{1}$ reported it as the most common major complication after the removal of oil. Retinal redetachment in diabetic eyes could be more serious because it is frequently associated with intractable rubeosis iridis. ${ }^{10}$

Except for silicone oil removal, glaucoma surgery has rarely been attempted in oil filled eyes with uncontrolled postoperative IOP. ${ }^{11}{ }^{12}$ Because traditional filtering surgery is technically difficult owing to conjunctival scarring resulting from the multiple retinal surgery, artificial drainage devices or cyclodestructive procedures may be the most appropriate means of lowering medically uncontrollable IOPs associated with intravitreal silicone oil. In seven eyes with uncontrolled glaucoma secondary to silicone oil injection Nguyen et al ${ }^{12}$ attempted glaucoma procedures, sometimes combined with silicone oil removal. Molteno implantations were performed in five of these eyes, with a success rate of $60 \%$ (3/5). Modified Schocket procedure, performed in one eye, was a qualified failure and Nd:YAG trans-scleral cyclophotocoagulation performed in another was a complete success.

Bloom et $a l^{4}$ have presented successful results of diode laser trans-scleral cyclophotocoagulation from 36 eyes with silicone oil induced glaucoma, but there was no mention of whether they performed TSCPC in the eyes with silicone oil or the eyes with silicone oil removed.

In the present study, the IOP of all the patients $(100 \%)$ was lowered below $20 \mathrm{~mm}$ $\mathrm{Hg}$ after treatment, and all patients were relieved of ocular pain and corneal oedema which were the causes of treatment in some patients. In lowering IOP, the success rate was $100 \%$, but it was reduced to $81.8 \%$ because two of the patients (cases 2, 10) lost light perception after the treatment. In case 2, poorly controlled IOP for 14 months before the treatment caused the total cupping of disc and the remaining visual field of the central island disappeared immediately after the treatment. In case 10, the cause of visual loss was thought to be haemophthalmos secondary to the aggravation of proliferative diabetic retinopathy. Hypotony or sympathetic ophthalmia, which is the potential complication of cyclodestructive procedures, did not occur in the present study.

In conclusion, it can be stated that semiconductor diode laser appears to be a promising method for the treatment of medically uncontrolled glaucoma secondary to intravitreal silicone oil injection.

Supported by a grant no 02-97-328 from the Seoul National University Hospital Research Fund.

1 Casswell AG, Gregor ZJ. Silicone oil removal. II. Operative and postoperative complications. $\mathrm{Br} \quad \mathcal{f}$ Ophthalmol 1987;71:898-902.

2 Kosoko O, Gaasterland DE, Pollack IP, et al. The Diode Laser Ciliary Ablation Study Group. Long-term outcome of initial ciliary ablation with contact diode laser transscleral cyclophotocoagulation for severe glaucoma. Ophthalmology 1996;103:1294-302.

3 Gaasterland DE, Pollack IP. Initial experience with a new method of laser transscleral cyclophotocoagulation for ciliary ablation in severe glaucoma. Trans Am Ophthalmol Soc 1992;90:225-46.

4 Bloom PA, Tsai JC, Sharma K, et al. "Cyclodiode" trans-scleral diode laser cyclophotocoagulation in the treatment of advanced refractory glaucoma. Ophthalmology 1997;104:1508-19.

5 Ando F. Intraocular hypertension resulting from pupillary block by silicone oil. Am f Ophthalmol 1985;99:87-8.

6 Lean JS, Stern WH, Irvine AR. Classifications of proliferative vitreoretinopathy used in the silicone oil study. Ophthalmology 1989;96:765.

7 Hennis HL, Stewart WC. Semiconductor diode laser transscleral cyclophotocoagulation in patients with glaucoma. Am $\mathcal{F}$ Ophthalmol 1992;113:81-5.

8 Casswell AG, Gregor ZJ. Silicone oil removal. I. The effect of the complications of silicone oil. Br f Ophthalmol 1987; 71:893-7.

9 Barr CC, Lai MY, Lean JS. Postoperative intraocular pressure abnormalities in the silicone study. Ophthalmology
1993;100:1629-35. 
10 Pearson RV, Mc Leod D, Gregor ZJ. Removal of silicone oil following diabetic vitrectomy. Br $\mathcal{f}$ Ophthalmol 1993;77: following 204 .

11 Riedel KG, Gabel VP, Neubauer L. Intravitreal silicone oil injection: complications and treatment of 415 consecutive patients. Graefes Arch Clin Exp Ophthalmol 1990;228:19-23.

12 Nguyen QH, Lloyd A, Heuer DK. Incidence and management of glaucoma after intravitreal silicone oil injection for complicated retinal detachments. Ophthalmology 1992;99: 1520-6. 13 Federman JL, Schubert HD. Complications associated with
the use of silicone oil in 150 eyes after retina-vitreous surgery. Ophthalmology 1988;95:870-6.
14 Laroche L, Pavlakis C, Saraux H, et al. Ocular findings following intravitreal silicone oil injection. Arch Ophthalmol 1976;94:612-5.

15 Burk LL, Shields MB, Proia AD, et al. Intraocular pressure following intravitreal silicone oil injection. Ophthalmic Surg 1988;8:565-9.

16 De Corral LR, Cohen SB, Peymen GA. Effect of intravitreal silicone oil on intraocular pressure. Ophthalmic Surg 1987; 18:446-9.

17 Moisseiev J, Barak A, Manaim T. Removal of silicone oil in the management of glaucoma in eyes with emulsified silicone. Retina 1993;13:290-5. 